\title{
The World View of Dialectical Dualist: The Dialectical Relation View of the Subjective World and the Objective World
}

\author{
Yong Duan \\ College of Engineering, China Agricultural University, Beijing, China
}

Email address:

duany1@163.com

\section{To cite this article:}

Yong Duan. The World View of Dialectical Dualist: The Dialectical Relation View of the Subjective World and the Objective World. International Journal of Philosophy. Vol. 9, No. 2, 2021, pp. 78-84. doi: 10.11648/j.ijp.20210902.11

Received: March 22, 2021; Accepted: April 8, 2021; Published: April 23, 2021

\begin{abstract}
Science is theories divided into many branches. Philosophy is the whole theory without branches, it is the most abstract theory. The main function of philosophy is to provide people with a holistic world view, a rational belief, the ultimate standard of value and the ultimate standard of truth. The world view provided by philosophical ontology is the world view of the whole, which embraces all valuable but maybe not objective and real things. The physical world view is one part of the metaphysical world view. The objective world includes material and Tao. Tao includes relations and laws. The subjective world includes Xin, Xing, Qing, Yi and thought products. Xin means the thought. Xing refers to the human nature, needs and interests. Qing includes emotion, feeling and vision. Yi means people's attitude, will, perseverance and decision-making. Thought products include knowledge, hypotheses, myths, lies, arts, religion, prejudice, and so on. The subjective world is part of the objective world. And the objective world we think and say is part of the subjective world. It is the objective world 2 , not the objective world 1. In fact, what we call the objective world 1 is also what we think and what we say, and also a part of the subjective world. The objective world and the subjective world are the dialectical unity of layer upon layer nesting and infinite circulation. The abstract way of understanding is the colored glasses that we have to wear. Abstraction inevitably brings contradiction.
\end{abstract}

Keywords: Ontology, World View, Dialectical Unity, Cycle, Abstract

\section{Introduction}

Philosophy has a long history, there are many great philosophers and many famous philosophical theories. But what exactly is philosophy? What is the use of philosophy? These most basic questions have been opinions vary. This has become a great scandal for philosophy and a great shame for philosophers. The basic problem of philosophy is the relationship between matter and consciousness. Materialism and idealism have argued for thousands of years, but there is no result up to now. This paper will explain the role of philosophy, at the same time put forward a new world view, that is, the dialectical picture of the relationship between the subjective world and the objective world in the hope of ending this debate.

\section{The Basic Idea to Understand Philosophy}

To understand philosophy, we must first understand how philosophical problems arise, what problems it want to solve, and what goals to achieve. That is to say, we must first find a basic idea for the development of philosophy. The basic idea is that early philosophers tried to use philosophy to solve all problems.

There are general clinics and branch clinics in hospital. The sub-clinics include internal medicine, surgery, paediatrics, gynecology and so on. Similarly, science is branch theories or branch wisdom, including maths, physics, chemistry, biology and so on. But philosophy is general theory, general wisdom, or non-subject theory, non-subject wisdom. A discipline in science only studies the commonalities of certain things. For 
example, biology only studies the commonalities of living things, anthropology only studies the commonalities of human beings. Or a discipline only studies one aspect of all things. For example, optics studies only the optical properties of all things, acoustics studies only the acoustic properties of all things. But philosophy is the most abstract theory. It deals with the commonality of all things, the commonality of all aspects. "Metaphysics" means more abstract than physics.

More than two thousand years ago, the ancient Greek geometrician Euclid established a huge theoretical system of geometry, which starts from several axioms and deduces a series of theorems, which can solve various problems. Philosophers hope to find the origin first, and then start from the origin to establish a system of theorems from top to bottom as geometry dose. Therefore they can deduce all the necessary conclusions and establish the most complete world outlook to solve all the problems of understanding and reforming the world.

It is not easy to live. There are all kinds of pain and disaster. We must fight with the sky, ground and people to survive and to live a happy life. But these struggles have had their successes and failures, and sometimes the failures have been terrible and bloody.

If you want to succeed, you must accept the lessons of failure, find the causes of failure, and find the methods to solve various problems. Sometime finding one cause can solve a lot of problems, and then people think, it would be great if finding one cause could solve all problems. Such a cause is called the "origin", which is the reason of all problems The word "philosophy" in Greek language means to love wisdom, of course great wisdom is needed to find solutions to all problems.

Aristotle, Hegel and others tried to establish a theoretical system starting form the origin that could solve all problems, but the systems they established could not solve any problems, and the first step of searching for the origin was not done well.

Philosophers hold that the origin from which all conclusions can be derived is the most abstract noumena, and the theory that studies noumena is called ontology. Various theories have been arguing about origin and noumenon. So philosophy remained there, studying nothing but the origin. So it is not that philosophy only wants to deal with the origin, but that it is incapable of dealing with anything else. A lot of problems were caused to study the origin, such as truth standard, cognition method, dialectical logic, value standard and so on. These problems have not been solved, so philosophy become a tangle without a clue.

Is philosophy useless at all? Of course not. Philosophy plays a big role. Neither exalting it to the sky nor burying it in the ground, philosophy is equal to other subjects. What is the main function of philosophy? It provides people with a holistic world view, a rational belief, the ultimate standard of value and the ultimate standard of truth.

\section{Two Kinds of World Views}

There are two kinds of world views: the metaphysical world view and the physical world view. The physical world view is the world view provided by the various disciplines of science, including astronomy, physics, history, Darwinian evolution, general evolution, and so on. The metaphysical world view is provided by philosophical ontology, it is the whole world outlook. The physical world view is one part of the metaphysical world view.

Why? Because scientists only want to provide us with an objective and realistic view of the world, but there are many important and valuable things that are not objective and true. First of all, many contents of religion are unreal. Secondly, most artistic images and plots are unreal. What's more important, a lot of content of science is unreal. If we believe that there is no absolute truth in the world, then all scientific theories may be wrong and may not belong to the objective reality of the world. You can say that these false things do not exist, but you cannot say that they have no value. We can even say that in most cases the value of science, art and religion is far greater than the real world.

Therefore we can come to a conclusion that if we ignore the existence of these false things, it only shows that our world view is incomplete. If we say that everything in the objective world is objective and true, then these false things do not belong to the objective world, but to the subjective world. So the objective world is only a part of the world. The world view provided by science only describes the objective world, so the world view provided by science is not the complete world view, only the metaphysical world view provided by philosophy is the complete world view, which embraces everything, especially those things that may be not objectively real but have great value.

The world view of Dialectical Dualism is a new world outlook of metaphysics, which believes that the existence of the world includes two parts: the subjective world and the objective world, and they are dialectical and unified relation that contain each other. Existence is not equal to objective existence. The existence includes objective existence and subjective existence. What exists in the subjective world may not be objective, but it is also a kind of existence.

Dialectical Dualism believes that the objective world includes Matter and Tao. The Matter is material, the Tao is relation and law. The relation includes the same relation, the similarity relation, the space structure relation, the time relation, the gravity relation, the magnetic force relation, the authority relation and so on.

The Material is opposed and relative to relations and laws. For example, when we study the motion of a small piece of iron, and we do not care about the internal structure or the laws of its internal motion, then the iron is the material. But when we want to study the internal composition of the iron, the mass of iron is no longer material. When we say that the iron is made of iron atoms, we are thinking of the iron atoms as material, and the way the iron atoms are arranged is the relation or law. And when we look at the composition of iron atoms, the iron atoms are no longer material.

Therefore, it can be said that there is no material in the world, and all objective existence is a system composed of 
certain relations and laws. Time is a kind of relation, space is a kind of relation, energy is also a kind of relation. Energy is the possibility of one matter acting on another.

The existence of subjective world includes Xin, Xing, Qing, Yi and Thought Products.

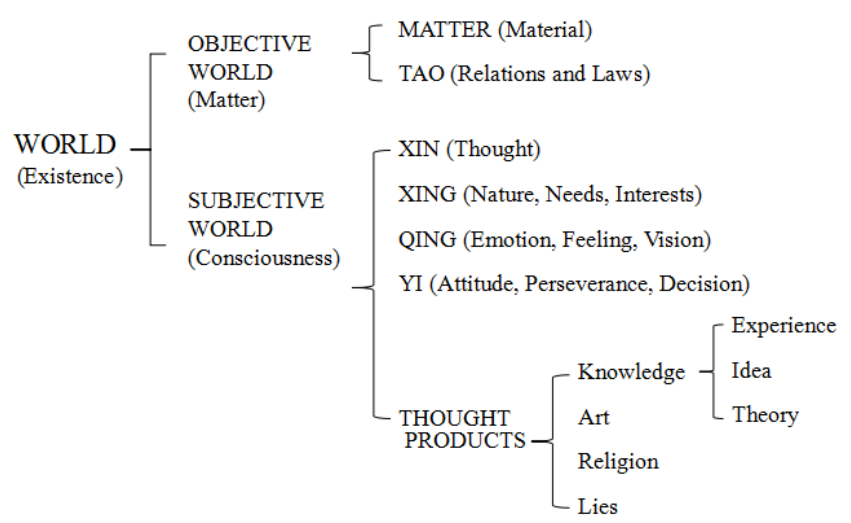

Figure 1. Composition of the World.

In Chinese, Xin means the heart, here it refers to the thought in the brain. The thought includes perceptual thinking and rational thinking. Xing refers to human nature, needs and interests. Nature includes human temper, disposition, habits, character, cultivation, sentiment and spirit. Qing includes emotion, feeling and vision. Feeling includes bitterness, joy, happy, anger, sorrow, fear, love, evil, surprise, worry and so on. Feeling is the main driving force to produce the will of behavior. When people's feelings develop into passions, it will produce the biggest driving force to behavior, and people will burst out with great creativity, fighting power or destructive power. Emotion is relatively short feeling, including anxiety, excitement, panic, satisfaction, pride, etc. Vision is relatively rational feeling, such as wish, dream, ideal, yearning, and so on. Yi means the direct power that governs people's behavior, including people's attitude, will, perseverance and decision-making. Moral ideas belong to attitude or will. Decisions include concrete decisions and abstract decisions. All normative theories are abstract decisions, including technology, principles, laws, regulations, systems, ethics, customs, etc.

Thought products include knowledge, hypotheses, assumptions, fantasy, myths, fairy tale, lies, arts, religion, prejudice, and so on. Among them, knowledge includes experience, ideas and theories. Experience includes both direct experience and indirect experience. Direct experience includes direct experience of external things and experience of subjective world of one's own body and mind, in which there are many illusions. Ideas include opinions, prejudices, hypotheses, assumptions, impressions, and half-baked ideas. Theories include scientific theories, philosophical theories, and all kinds of fallacies. Experience, idea and theory describe abstract Matter and Tao. Knowledge is the most objective consciousness, all other consciousness are less objective or no objective. Knowledge creates an objective world, which can be called objective world 2, knowledge is the content of objective world 2 .

In the subjective world, the Xing of people (nature, needs, interests) and emotion are the id; the feeling, thought, attitude, will, decision, experience and idea are the ego; the vision and science, art, religion of thought products are the superego.

\section{Dialectical Relation of Two Worlds}

There are the sun, the moon, the stars, tables, chairs and human society in the objective world. And there is the human brain, the movement of brain and the consciousness generated by brain movement. Human consciousness produces the subjective world, in which there is what I see and think. I see tables and chairs, I see people and their behaviors, I see the sun, the moon and the stars, I think of the Big Bang, I think of the wave-particle duality of light and so on. These things constitute the objective world, which is inside the subjective world. This objective world is objective world 2 . The real objective world is objective world 1 .

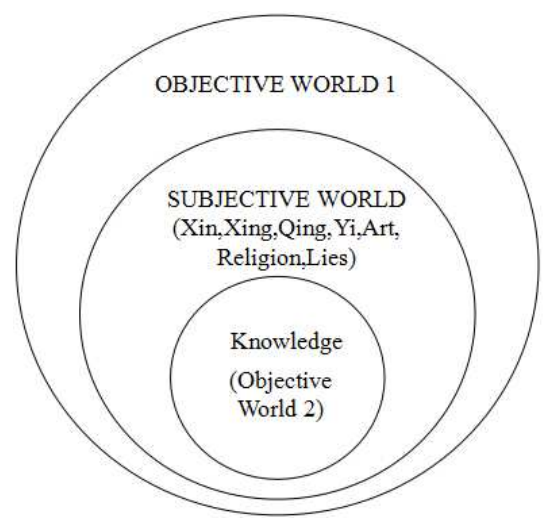

Figure 2. Dialectical Relation of the Two World.

The objective world we think and talk about is not the real objective world, but is made of our experience, ideas and theories. It is an artificial objective world. For example, when we think of a stone, we think of its round or irregular shape, of its hardness, of its colour being white or grey, and so on. These shapes, hardness, and color are our sensory experience of a certain thing, and the combination of sensory experience makes up an object. The object, which is made up of sensory experience, is often different from the real object. The real stone has a complex composition and structure inside. These objective content is much more than we can think of. So the object world we think and talk about is actually part of the subjective world, it is the objective 2, not the objective world 1 .

The objective world 2 is in the subjective world, it is the true subset of the subjective world. The subjective world is in the objective world 1 , it is the true subset of the objective world 1. Because the content of the subjective world is human consciousness, which is the function of the brain. The brain is an objective material system, a part of objective world 1 . Human experience has the otherize character, it is something we have to accept. Only by acknowledging that the objective world is outside of us can cognition get logical unity.

Now let's look at the objective world 1. Is the objective world 1 really objective? The objective world 1 we're talking about here is also something we're thinking about. I wouldn't be able to say it if I hadn't thought about it. Now that I'm thinking and 
talking about the objective world 1, it is also part of the subjective world, essentially it is objective world 2 . That is to say, there is a subjective world outside the objective world 1, and there is an objective world outside the subjective world.

And so on, layer upon layer nesting, endless loop. The relation between the subjective world and the objective world belongs to the dialectical unity relation, or the relation between matter and consciousness is the dialectical unity relation. This is the world view of dialectical dualism, the most fundamental and overall world view that metaphysics of philosophy should present to the public.

The person in the picture below is holding an image. In the image there is a person, herself, who is holding the same image, in which there are smaller images, and so on and so on. This also happens when looking at a mirror, with another mirror placed opposite. You can see an infinite number of mirrors reflecting off each other. This is called the Droste effect, a visual form of recursion.

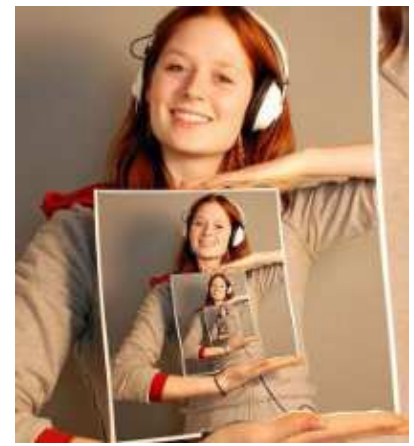

Figure 3. Droste Effect.
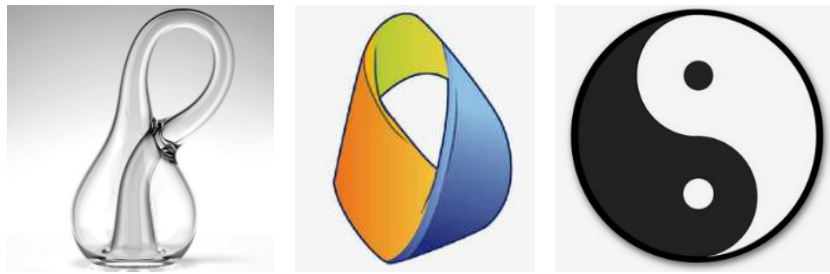

Figure 4. Klein Bottle, Mobius Belt, Yin Yang Diagram of Taiji Theory.

Dialectical logic does not conform to the rules of formal logic, but it is the commonness of many things, which is a logical relationship that we have to admit. Phenomena such as Droste effect, Klein bottle and Mobius belt all provide visual images of dialectical unity relations. The upper and lower sides of the Mobius belt are connected, and the inner and outer sides of the Klein bottle are connected. When we are children, we all heard such a story: Once upon a time, there was a mountain. In the mountain there was a temple. In the temple there was an old man telling a story. What was the story about? Once upon a time, there was a mountain. In the mountain there was a temple. In the temple there was an old man telling a story. The story could go on and on forever.

In the Yin Yang diagram of Chinese Taiji theory, Yin is a black fish and Yang is a white fish. The eye of the white fish is black, the eye of the black fish is white. The black eye of the white fish is actually the black fish, so there is white eye in the black eye and there is black eye in the white eye. The two fish meet head to tail and meet tail to head, which can represent the relationship of mutual transformation and mutual inclusion.

This relation of dialectical unity is not new to us, and many people are aware of its profound philosophical significance. But what it means, no one has been able to describe clearly. This dialectical view of the world did not become the most fundamental overall view of the world that metaphysics of philosophy should present to the public. The Chinese idea of Taiji Yin Yang is similar to this world view, but it did not said that the Yin and Yang represent the subjective world and objective world.

The science of astronomy, physics, general evolution and other disciplines also provide us with a world view, but science only describes the objective world. Philosophy is different from science. The basic problem of philosophy is the interrelation between matter and consciousness. Therefore, only philosophy can put forward the picture of the dialectical relationship between the subjective world and the objective world, and the objective world described by science is only one part of this picture.

The world that scientists study is the world they see and think, that is, the objective world 2. The so-called "study" is you to see, to think. If you do not see, do not think, you can not study. So scientists can only study the objective world 2 . It is impossible to study the objective world 1 . The objective world 2 is only a part of the subjective world, can not go beyond the subjective world. Just like Sun Wukong, he can never jump out of the palm of Buddha's hand. Because Buddha wrote the word "Subjective World' on his hand. So the world described by science is incomplete, and science can never replace philosophy.

The objective world 1 can only be pointed at, can not be described. As soon as you try to describe it, it must immediately turn to objective world 2 , no longer objective world 1.

Scientists know only to look at the world, philosophers know not only to look at the world but also to look at himself. Philosophers know that there is subjective element in our understanding of the world and that consciousness is the origin. The ancient Greek philosopher Thales was asked, "What is the hardest thing?" He replied, "Know yourself." These words were inscribed on the pillars of the temple of Apollo at Delphi. Therefore, the world described by scientists is only the surface world, while the Dialectical Dualism world picture is the deep structure of the world.

I am a part of the objective world, and the objective world is a part of me. Because the world is in my eyes, the world is in my heart. The sea is bigger than the land, the sky is bigger than the sea, the human mind is bigger than the sky. Wang Yangming said, There is no matter outside the mind. There is no event outside the mind. There is no law outside the mind." Lu Xiangshan said, "My heart is the universe, and the universe is my heart." [1] Schopenhauer said, "The world is my representation, the will is the essence of the world." [2] The Diamond Sutra says that all phases are false. In this sense, I 
am the whole world, I am the God. The so-call "God" means each subject.

"Who am I? Where do I come from? Where am I going?" That's Plato's question. Scientists think they have already answered that question, but they can't. Why can't scientists answer this question? Because they don't understand that the objective world is part of the subjective world. For this reason, when they encounter some paradoxes in quantum mechanics and other disciplines, they are easily lost, their worldview is easily overturned, and they can't understand dialectical logic. Only philosophy can eliminate this confusion, only philosophy can provide the foundation for science.

\section{Colored Glasses}

Why are the subjective world and the objective world dialectically united? Because we wear a pair of colored glasses. We have to rely on our senses and brains to do science and to understand the world, our senses and brains have limitations like a pair of colored glasses.

Scientists don't realize that they are wearing colored glasses when they see the world. If they see everything red, they assume that the physical world is made up of red elements. They don't believe that the red color comes from their own glasses. Philosophers are aware of this, which is the Copernican Revolution of Kant: not that our understanding conforms to the object, but that the object conforms to our understanding. [3]

Why did Kant say that the object must conform to our understanding? The main reason is that we have to use abstract method of understanding. This abstract method is a pair of colored glasses that we have to wear.

What is a chicken plus a dog? Is it equal to two chickens or two dogs? Obviously neither. But we can say that one plus one equals two, because we have made abstraction first before we do this calculation. What does it mean when we say "one"? It is an abstraction of a chicken, a dog, a person, an earth, everything. Scientific research cannot do without formal logic, and the premise of formal logic is abstraction. So scientific research can never do without abstraction. The abstract process can only take place in the subjective world. In the objective world there are only concrete things, there are no abstract things. In the concrete objective world, no two leaves are the same, and one is never equal to one. In the abstract subjective world, one can be equal to one. So scientific research can never jump out of the subjective world.

According to Hegel, the abstract view of identity puts identity and difference in opposition, and regards identity as only formal, such as A is A, A cannot be both A and -A. Hegel said this view of identity is a one-sided and isolated analytical method, which is very ridiculous. [4] Lenin excerpted for several times and agreed with Hegel's criticism of abstract and concrete identity in his Notes on Philosophy.

It was a very important philosophical discovery that Hegel found the distinction between concrete identity and abstract identity. Hegel's mistake was to forget that abstract identity is not a metaphysical claim, but a principle of reasoning in most natural scientific theories, it belongs to formal logic. Hegel's denial of abstract identity is to fight against all scientific theories. You can not say that all scientific theories are ridiculous. Formal logic is a distortion of the objective world, is the colored glasses of human beings. But scientific research can not do without this colored glasses, so we must accept both formal logic and dialectical logic. However, formal logic and dialectical logic are contradictory. How to unify them? The formal logic must be regarded as the logic of the objective world 2 and subjective world, the dialectical logic must be regarded as the logic of the objective world 1, so that the two can be unified.

Human knowledge is limited. We need to use limited knowledge to understand the infinite world and the infinite development of the world. How to do? The solution is to rely on the transcendence of consciousness, that is to obtain universal laws by abstract method. We can assume universal laws universally applicable, and we can strategize at home and win from thousands of miles away. There are many abstract theories in every science. When philosophers attempt to use one theory to solve all problems and find the root cause of all problems, abstraction is needed even more.

Einstein said, the most incredible thing in the world is that the world is conceivable. Althought our subjective world can transcend the objective world, but the transcendence is subjective, flawed or wrong.

There are three major puzzles in philosophy: system puzzle, method puzzle and object puzzle. The system puzzle means that theories have beginning and end, how can we explain the infinite world and the infinite development of the world with a finite theory. The method puzzle means that the basic method of cognition is induction, but it can not reach complete induction, so it can not achieve necessity, and it must take a part for the whole. The object puzzle means that the object of knowledge should be the whole, but should it include the subject himself? To include himself is to repeat, not to include himself is not comprehensive.

How to solve the three puzzles? The way to solve the system puzzle is to rely on the transcendence of consciousness, that is to use abstract methods to obtain universal laws. However, when we abstract, we encounter the method puzzle. Because the premise of abstraction is induction, and induction can not achieve complete induction, so we can not achieve necessity, must take a part for the whole. So what do we do? There is no way, we have to take a part for the whole, we must take a part for the whole. Although it can lead difference between our understanding and the objective world, this is the only way we can understand the infinite world, this is the colored glasses we have to wear.

Thus the object puzzle arises, that is, the problem of whether the object of cognition contains the subject himself. It is generally believed that the object of knowledge is of course the whole, and of course the subject himself is included in the whole, which is not repeated and is comprehensive. This is not the case. Because the colored glasses of the abstract method make the difference between our knowledge and the objective world. The world we know is not the objective world outside 
the subjective world, but the objective world inside the subjective world. It is the objective world 2, not objective world 1. Therefore, the philosophical world outlook must place the objective world within the subjective world of a person himself and consider the subjective world to be greater than the objective world. This is what the object puzzle really means. In other words, we must understand the dialectical unity between the subjective world and the objective world, and we must take both consciousness and matter as the origins.

If the theory of Materialism is thoroughgoing, it is bound to lead to idealism. At the same time thoroughgoing idealism is bound to lead to materialism. [5]

\section{Dialectical Corresponding Relation}

What is abstraction? Abstraction is simplification. For example, a chicken has many properties, it has a comb, wings, it has life and complex structure. I don't see any of them, I just see that the number of it is one, and I take all other properties out of my subjective world. That's abstraction.

Our brain capacity is limited, and the objective and concrete world contains infinitely complex and numerous information. We must simplify the world to understand it. Therefore, all scientific theories can only be composed of abstract concepts and abstract theories.

Only abstraction can lead to prediction. For example, foreigners see that they can make money in Beijing, Shanghai and Shenzhen, so they abstract it and conclude that there is a high probability of making money in other place in China. This abstract understanding can produce scientific predictions to guide future investments. On the contrary, if we only stay in the specific individual things, no matter how accurate it is, it can not lead to scientific prediction. Without prediction, we can't make decisions, and can't seek benefits in practice.

Abstraction is the way of thinking that we must use, the colored glasses that we have to wear. The abstraction inevitably brings contradiction and dialectical logic. Because the objective world is concrete, the concept is abstract. An abstract concept can be related to many concrete things, and a concrete thing can be related to many concepts. For example, the concept of life is an abstract generalization of all living things, so life is related to many specific living things, such as people, eggs, trees, bacteria, etc. At the same time an egg can be related to countless concepts, such as hard, oval, white, crisp, calcium, life and nutrition. This kind of relation is called dialectical corresponding relation.

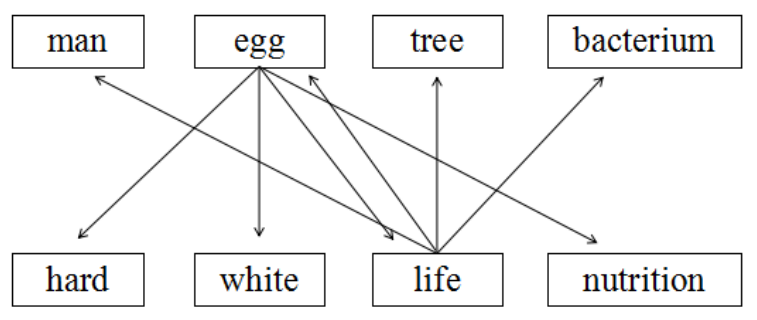

Figure 5. Dialectical Correspond Relation.
This kind of dialectical corresponding relation inevitably brings many contradictions. For example, ancient Chinese philosopher Gongsun Long said that a white horse is not a horse. Because a horse is an abstract concept, a white horse is a concrete horse, not an abstract concept.

A piece of paper has two sides, we call the top side as " $\mathrm{A}$ ", the bottom as "-A". If the top side could go on forever, any part of it would be A. But for the Mobius strip, the top side and the bottom are connected. So top can be equal to bottom, $\mathrm{A}=-\mathrm{A}$. The inside of Klein bottle can be equal to the outside. At the poles of the earth, south can be equal to north. You can step twice into the same river, at the same time, you can't step twice into the same river.

Dialectical corresponding relation makes a great difference between the cognition of concept composition and the objective world itself. This difference brings us a lot of trouble, but there is no way. We have to use the abstract way to understand the world. We can't do without this colored glasses. No matter how the cognition changes, it can't become the objective world and its movement itself. This is what Lao Tzu said, "The Tao can be described, but it is not the normal Tao."

The opposition of contradictions is abstract opposition, and the unity of contradictions is concrete unity under certain conditions. For example, at a crossroad, the north and the south can't go while the east and the west go, they are in contradiction. So how to achieve the unity of the contradiction? If an overpass is built, east and west, north and south can go at the same time. The overpass is the specific condition that realizes contradiction to unify. In the objective and concrete world, there are no contradictions.

All contradictions are made by people with the colored glasses. Therefore, all contradictions can be unified in the objective and concrete world. Why can't many people understand dialectics? Because it's really ridiculous. It doesn't exist in the objective world. Dialectics exists only in the subjective world or in the relationship between the subjective world and the objective world. Because our human understanding is subjective, we can't do without colored glasses, so we have to accept dialectics, we have to accept the dialectical unity between subjective world and objective world.

In fact, all the ways of cognition are colored glasses, are a distortion of the objective world. For example, human vision can only see visible light, human sense of smell, hearing, touch are much worse than animals. Human do not have the sonar system like bats. Many animals can see we can't see. Our senses are all colored glasses, and so are all our ways of thinking.

The mistake of the Materialism is to deny the use of colored glasses, saying that the concrete material world will not be distorted by colored glasses, and that wearing colored glasses one can see the objective concrete world as it is. They say that what scientists study is objective world 1 , not objective world 2. If that were true, there would be no need for philosophy. The second mistake of the Materialism is to take concrete matter as the origin and oppose abstract Tao as the origin. 
Although concrete matter is the real origin of the world, it is not what we need most. What we need most is abstract knowledge. The method of abstract understanding is colored glasses.

Objective idealism also denies the role of this colored glasses. They say that abstract ideas, Tao and objective laws are not what we see through colored glasses, but what the objective world itself possesses. They do not understand that Tao of the objective world itself is not the direct source of knowledge. The direct source of knowledge can only be observation of phenomena. The understanding of Tao comes into being only after the phenomena are abstracted. Tao is not the criterion of testing truth, either. The process of testing truth in practice is the process of observing new phenomena.

Subjective Idealism holds that the subjective world is the origin and the objective world is in the subjective world. But they didn't see that the subjective world is also in the objective world. We must acknowledge that the otherize character of consciousness can only come from the objective world.

\section{Conclusion}

The main function of philosophy is to provide people with a holistic world view, a rational belief, the ultimate standard of value and the ultimate standard of truth. The world view provided by philosophical ontology is the world view of the whole, which embraces all valuable but maybe not objective and real things. The physical world view is one part of the metaphysical world view. The subjective world is part of the objective world. And the objective world we think and say is part of the subjective world. The objective world and the subjective world are the dialectical unity of layer upon layer nesting and infinite circulation. The abstract way of understanding is the colored glasses that we have to wear. Abstraction inevitably brings contradiction.

\section{References}

[1] Guo Qiyong. History of Chinese Philosophy (In Chinese). Higher Education Press, 2006: pp. 311-312, 294.

[2] Arthur Schopenhauer. The World as Will and Representation (In Chinese). Commercial Press, 2009: pp. 25-27.

[3] Imanuel Kant. Critic of Pure Reason (In Chinese). Central China Nomal University Press, 2000: pp. 17.

[4] G. W. F. Hegel. Little Logic (In Chinese). The Commercial Press, 1980, $2^{\text {nd }}$ Ed.: pp. 247-249.

[5] Yong Duan. Taiji Evolutionism (In Chinese). The second volume. Four Seasons Publishing House, 2017: pp. 251.

[6] Basseches, M. (2005). The development of dialectical thinking as an approach to integration. Integral Review, 1, 47-63.

[7] Basseches, M. (1980). Dialectical schematas: A framework for the empirical study of the development of dialectical thinking. Human Development, 23 (6), 400-442.

[8] Bolis, D., Schilbach, L. (2018). "I interact therefore I am": The self as a historical product of dialectical attunement. Topoi, 39, 521-534.

[9] Buss, A. R. (1976). Development of dialectics and development of humanistic psychology. Human Development, $19,248-260$.

[10] Dafermos, M. (2015). Reflection on the relationship between cultural-historical theory and dialectics. Psychological Science \& Education, 20 (3), 16-24.

\section{Biography}

Yong Duan (1967-), male, lecturer of China Agricultural University, master of philosophy, engaged in ontology, philosophy of science, system science, etc. 